\title{
Defining Satellite Robotics Surgery using IOT
}

\section{Sadique Shaikh*}

Department of Management \& Science (IMS), Bhusawal, India

Received: 制 October 27, 2018; Published: 制 October 30, 2018

*Corresponding author: Sadique Shaikh, KYDSC Trust's, Department of Management \& Science (IMS), Bhusawal, MS, India

\section{Opinion}

Now days Internet of Things (IoT) is making everything, remote control and remote operating possible and change imagination of objects communication into reality using Satellite based USN (Ubiquitous Sensing Network). IoT is all ultimate communication technology where not only living but also all non-living things can communicate, command, control, process using their unique RFIDs and USN. Hence it would be possible what I hypothesis "Satellite Robotic Surgery using IoT". I have drawing one model to explain how this happen will possible in near future labeled as "Satellite Robotics Surgery Model (SRSM)". Let me explain you how it would be engineer and functional (Figure 1).

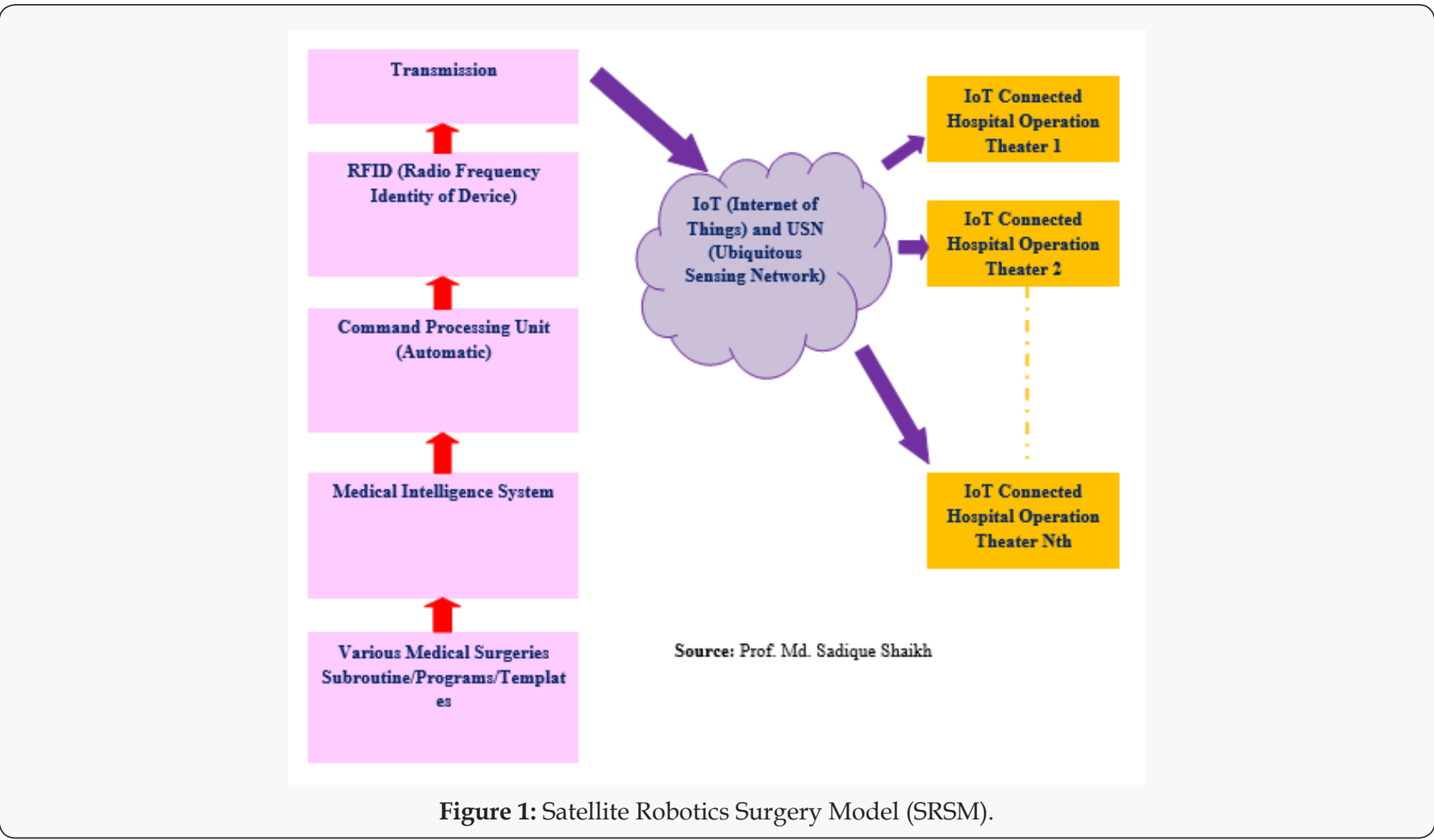

To implement Satellite based robotics surgery using IoT very first requirement is Various Medical Surgeries Subroutine/ Programs/Templates which passes through Medical Intelligence System to decide which surgery procedure requested from client hospital from which country and what surgical method is efficient from the alternatives subroutines and what are seriousness, complication and nature of surgery. After medical intelligence decision support system decision commands prepared and send to command processing unit. The function of command processing to caliber command with precise control, time management, signal conditioning and data acquisitions. At next level whole process included its RFID and streaming through transmission unit to client's hospitals from 1, 2, $3 \ldots$ Nth using USN and IoT with satellite-based communication worldwide with granting to requests of number of client's hospital who requested for satellite based robotic surgery using IoT. 


\section{Conclusion}

I have discussed how Satellite Robotic Surgery possible using IoT and USN with the help of Satellite Robotics Surgery Model (SRSM)". The big advantage of this technology surgical operation possible from expert programs with absence of doctors but one big disadvantage would be if data streaming command communication failure or break at any point become cause of stop remote surgery or obstacle because of distortion in signal reception at client's hospitals.

\section{Acknowledgment}

I really thankful to my wife Safeena Shaikh for her moral support my sons Md. Nameer Shaikh \& Md. Shadaan Shaikh for their love which keeps me fresh with new ideas and my close friend Tanvir Sayyed for her positive support with me. I acknowledge this work to my friends Jyoti Firke and Ritashri Cahudhari for encouragement and equally to Dr. BN Gupta who inspired me.

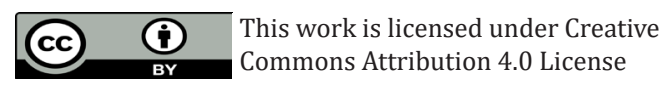

To Submit Your Article Click Here: $\quad$ Submit Article

DOI: $10.32474 /$ LOJMS.2018.02.000133

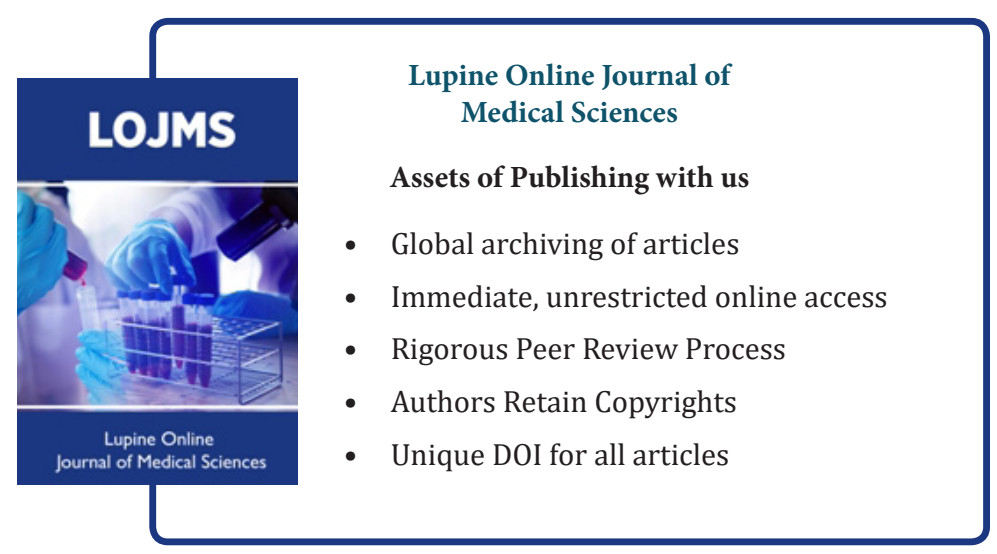

